\title{
Intraindividual relations between achievement goals and discrete achievement emotions: an experience sampling approach
}

Article

Accepted Version

Goetz, T., Sticca, F., Pekrun, R., Murayama, K. and Elliot, A. J. (2016) Intraindividual relations between achievement goals and discrete achievement emotions: an experience sampling approach. Learning and Instruction, 41. pp. 115-125. ISSN 0959-4752 doi:

https://doi.org/10.1016/j.learninstruc.2015.10.007 Available at https://centaur.reading.ac.uk/48790/

It is advisable to refer to the publisher's version if you intend to cite from the work. See Guidance on citing.

To link to this article DOI: http://dx.doi.org/10.1016/j.learninstruc.2015.10.007

Publisher: Elsevier

All outputs in CentAUR are protected by Intellectual Property Rights law, including copyright law. Copyright and IPR is retained by the creators or other copyright holders. Terms and conditions for use of this material are defined in the End User Agreement. 


\section{www.reading.ac.uk/centaur}

\section{CentAUR}

Central Archive at the University of Reading

Reading's research outputs online 
Intraindividual Relations between Achievement Goals and Discrete Achievement Emotions:

An Experience Sampling Approach

Thomas Goetz and Fabio Sticca

University of Konstanz and Thurgau University of Teacher Education

Reinhard Pekrun

University of Munich

Kou Murayama

University of Reading

Andrew J. Elliot

University of Rochester

Author Note

Thomas Goetz, Department of Empirical Educational Research, University of Konstanz, Konstanz, Germany, and Thurgau University of Teacher Education, Kreuzlingen, Switzerland; Fabio Sticca, Department of Empirical Educational Research, University of Konstanz, Konstanz, Germany, and Thurgau University of Teacher Education, Kreuzlingen, Switzerland; Reinhard Pekrun, Department of Psychology, University of Munich, Munich, Germany; Kou Murayama, Department of Psychology, University of Reading, Reading, UK; Andrew J. Elliot, Department of Clinical and Social Sciences in Psychology, University of Rochester, Rochester, NY.

This research was supported by a grant from the Swiss National Science Foundation (SNSF) to the first author (100014_131713/1) and supported by a Research Chair grant awarded to Reinhard Pekrun from the University of Munich (VII.1-H172.10).

Correspondence concerning this article should be addressed to Thomas Goetz, University of Konstanz, Universitaetsstrasse 10, 78457 Konstanz, Germany, E-mail: thomas.goetz@unikonstanz.de 


\begin{abstract}
Theories on the link between achievement goals and achievement emotions focus on their withinperson functional relationship (i.e., intraindividual relations). However, empirical studies have failed to analyze these intraindividual relations and have instead examined between-person covariation of the two constructs (i.e., interindividual relations). Aiming to better connect theory and empirical research, the present study $\left(N=12010^{\text {th }}\right.$ grade students $)$ analyzed intraindividual relations by assessing students' state goals and emotions using experience sampling $(N=1,409$ assessments within persons). In order to replicate previous findings on interindividual relations, students' trait goals and emotions were assessed using self-report questionnaires. Despite being statistically independent, both types of relations were consistent with theoretical expectations, as shown by multi-level modeling: Mastery goals were positive predictors of enjoyment and negative predictors of boredom and anger; performance-approach goals were positive predictors of pride; and performance-avoidance goals were positive predictors of anxiety and shame. Reasons for the convergence of intra- and interindividual findings, directions for future research, and implications for educational practice are discussed.
\end{abstract}

Keywords: achievement goals, achievement emotions, intraindividual analysis, trait, state 
Intraindividual Relations between Achievement Goals and Discrete Achievement Emotions: An Experience Sampling Approach

"Tell me what you want and I tell you what you feel" (adapted proverb, Brillat-Savarin, $1825 / 1999)$

\section{Introduction}

Achievement emotions have attracted increasing attention during the last 20 years due to cumulative empirical evidence showing that they can exert profound effects on students' learning and academic agency. Achievement emotions shape students' learning behavior, influence their academic attainment, guide their decisions to persist or drop out of academic programs, and represent core elements of their psychological well-being (Pekrun \& Linnenbrink-Garcia, 2014). Given our current knowledge on the relevance of achievement emotions, it is important to examine their antecedents. Knowledge on the origins of achievement emotions is needed for the development of classroom practices and intervention programs that foster adaptive achievement emotions and reduce maladaptive emotions. Among the potentially relevant proximal antecedents of achievement emotions, students' achievement goals are likely of pivotal importance (Pekrun, Elliot, \& Maier, 2006; Huang, 2011; Linnenbrink-Garcia \& Barger, 2014). Learning environments, as distal antecedents of students' achievement emotions, could be designed in such a way that they positively influence students' achievement goals, thus also fostering their emotions.

Several theoretical models have been proffered to explain the link between achievement goals and emotions (e.g., Linnenbrink \& Pintrich, 2002; Pekrun et al., 2006, 2009), and numerous empirical studies have been conducted to test these models. However, while these theoretical models refer to within-person functioning (i.e., intraindividual relations), the available empirical evidence is nearly exclusively based on the analysis of between-person covariation of the two 
constructs (i.e., interindividual relations). Consequently, the existing empirical findings do not provide direct evidence on the validity of the theories.

Generally, most psychological theories focus on intraindividual psychological functioning, and the same holds true for educational theories of student learning. However, despite this within-person focus, empirical studies typically have examined interindividual (i.e., between-person) relations between variables. Voelkle, Brose, Schmiedek, and Lindenberger (2014) estimated that about $90 \%$ of empirical research in psychology is based on the analysis of between-person variation. However, it is not possible to infer intraindividual relations from findings on relations based on interindividual data (and vice versa), as both types of relations refer to different distributions of variables, namely to distributions within persons (intraindividual approach) versus between persons (interindividual approach; Molenaar, 2004; Molenaar \& Campbell, 2009). As noted by Schmitz and Skinner (1993, p. 1010), "These two correlations [i.e., interindividual vs. intradindividual correlations] are statistically independent, and their direction and magnitude can vary widely" (see also Schmitz, 1987; Voelkle et al., 2014). A classic example illustrating the independence of inter- and intraindividual relations was provided by Schmitz and Skinner (1993): The positive interindividual correlation between sleep duration and frequency of migraine headaches seemingly implies that sleeping late can lead to headaches (or vice versa). Such a conclusion would be misleading, however, because these two variables are correlated negatively within individuals, implying that headaches occur in combination with shorter duration of sleep.

The present study had two primary aims. First, we sought to replicate previous findings on the interindividual relations between three commonly endorsed achievement goals (mastery, performance-approach, performance-avoidance) and six discrete achievement emotions (enjoyment, pride, anxiety, shame, anger, boredom). To evaluate interindividual relations, we 
used self-report scales to assess students' relatively enduring, trait-like (henceforth "trait") achievement goals and emotions. Second, and most importantly, we sought to move beyond the traditional interindividual perspective by analyzing the intraindividual relations of these variables. To do so, we assessed students' state achievement goals and achievement emotions employing the experience sampling method (Hektner, Schmidt, \& Csikszentmihalyi, 2007) with multiple assessments within each student.

\subsection{Concepts of Achievement Goals and Achievement Emotions}

Achievement goals are defined as "competence-based aims used to guide behavior" (Elliot, Murayama, \& Pekrun, 2011, p. 632). Two basic types of achievement goals are mastery goals, which refer to attaining mastery standards and developing competence, and performance goals, which refer to attaining normative standards (i.e., performance relative to others; Linnenbrink-Garcia \& Barger, 2014), often to demonstrate competence. Further, in the trichotomous achievement goal framework (Elliot \& Harackiewicz, 1996), two types of performance goals have been differentiated, namely performance-approach goals, which refer to outperforming others, and performance-avoidance goals, which refer to not performing poorly relative to others. In the present research, we adopt this trichotomous goal framework, because the goals addressed in this framework are the most frequently endorsed by high school students (Elliot \& McGregor, 2001; Pekrun et al., 2006, 2009).

Achievement emotions can be defined as emotions regarding achievement activities or achievement outcomes (Pekrun, 2006). In addition to this object focus (activity vs. outcome), achievement emotions can be grouped according to their valence (positive vs. negative). Taking both object focus and valence into account renders a $2 \times 2$ taxonomy (Pekrun et al., 2006) grouping these emotions as follows: (a) activity/positive (e.g., enjoyment), (b) activity/negative (e.g., boredom, anger), (c) outcome/positive (e.g., hope, pride), and (d) outcome/negative (e.g., 
anxiety, hopelessness, shame).

\subsection{Previous Research}

1.2.1 Theoretical assumptions. Pekrun et al. (2006, 2009) developed a theoretical model that links the goals from the trichotomous achievement goal framework (i.e., mastery, performance-approach, and performance-avoidance; Elliot \& Harackiewicz, 1996) to various discrete achievement emotions. The authors grounded their work in Pekrun's (2006) controlvalue theory which posits that the perceived controllability and the subjective value of achievement activities and outcomes function as proximal antecedents of achievement emotions. Mastery goals are proposed to focus attention on the controllability and positive value of achievement activities, thus fostering positive activity emotions (e.g., enjoyment) and reducing negative activity emotions (e.g., boredom and anger). Performance-approach goals are proposed to focus attention on attaining success outcomes, the controllability of these outcomes, and their positive value, implying that they should promote positive outcome emotions (e.g., pride). Performance-avoidance goals focus attention on possible failure outcomes, the uncontrollability of these outcomes, and their negative value, implying that they promote negative outcome emotions (e.g., anxiety and shame).

1.2.2 Empirical findings. Based on empirical reviews by Huang (2011) and LinnenbrinkGarcia and Barger (2014), and an additional search of the literature using the PsycINFO and ERIC databases, we found that there are at least 94 studies on the relations between achievement goals and affect or emotions (77 studies were reported by Huang, 2011, 9 additional studies by Linnenbrink-Garcia and Barer (2014), and 8 additional studies were identified in our search). Overall, the findings support the predictions from Pekrun et al.'s $(2006,2009)$ model. Specifically, multiple studies have found that mastery goals relate positively to students' enjoyment (e.g., Daniels et al., 2008, 2009; King, McInerney, \& Watkins, 2012; Shih, 2008) and 
that performance-avoidance goals relate positively to students' anxiety (e.g., Bong 2009;

Duchesne \& Ratelle, 2010; Putwain \& Symes, 2012; Shih, 2005; Sideridis, 2008). Both of these links are well documented, and the findings are largely consistent across studies (Huang, 2011). For emotions other than enjoyment and anxiety, the empirical evidence for relations with achievement goals is scarce, but also largely supports the expected relations. For example, Daniels et al. $(2008,2009)$ found that mastery goals were negatively related to boredom and anger, King et al. (2012) found performance-approach goals to be positively related to hope and pride, and Pekrun et al. $(2006,2009)$ reported positive relations of performance-avoidance goals with hopelessness and shame.

All of the available studies, however, have examined the interindividual relations (i.e., between-person covariation) of achievement goals and emotions, with only two exceptions. Schantz and Conroy (2009) investigated the intraindividual relations between goals from the $2 \times$ 2 achievement goal framework and affect (happy vs. unhappy) during a round of golf (18 holes) in collegiate golfers. Goals and affect were assessed immediately before teeing off on every hole. Results showed that golfers reported higher levels of happiness at the beginning of holes if they had low performance-approach goals or low mastery-avoidance goals during the round (means over round) or endorsed lower-than-usual mastery-avoidance goals for that hole. Rebar and Conroy (2013) investigated the impact of experimentally manipulated state achievement goals from the $2 \times 2$ framework on undergraduate students' experiences of pride and shame following experimentally manipulated competence feedback. The assessment was embedded in a 24-round game of Tetris. Situation-specific achievement goals moderated the effects of feedback (competence, incompetence, no feedback) on pride and shame. In line with Pekrun et al.'s (2006, 2009) theoretical propositions, performance-approach goals enhanced pride responses to competence feedback, but did not have an impact on shame responses to incompetence feedback. 
By contrast, performance-avoidance goals enhanced shame responses to incompetence feedback, but did not have an impact on pride responses to competence feedback. Mastery goals had no impact on pride and shame responses to competence-based feedback.

In sum, while there are a number of findings on interindividual relations between achievement goals and achievement emotions that are in line with Pekrun et al.'s $(2006,2009)$ theoretical proposition; the scarce empirical evidence on intraindividual relations between achievement goals and emotions is restricted to a few emotions (happiness, pride, and shame). Furthermore, neither of the two existing studies on intraindividual relations examined the goalemotion link in a classroom setting.

\subsection{The Present Study}

We aimed to examine the relations between students' achievement goals and achievement emotions by analyzing both interindividual (i.e., between-person) and intraindividual (i.e., within-person) covariation in a classroom setting. Regarding interindividual relations, we expected to confirm the propositions by Pekrun et al. (2006; see Figure 1 for an overview) and to replicate the findings from previous studies: (1) mastery goals positively predict enjoyment and negatively predict boredom and anger, (2) performance-approach goals positively predict pride, and (3) performance-avoidance goals positively predict anxiety and shame. With regard to intraindividual relations, we aimed to investigate whether these theoretical propositions hold for intraindividual functioning. This is a critically important issue, given that the Pekrun et al. (2006, 2009) model, as well as other theories on the achievement goal-emotion link (e.g., Linnenbrink \& Pintrich, 2002), address the relations between achievement goals and emotions in terms of intraindividual psychological functioning (see Linnenbrink-Garcia \& Barger, 2014).

For the interindividual analysis, paper-and-pencil questionnaires were used to assess students' trait achievement goals and emotions related to four major subject domains 
(mathematics, German, English, and French). For the intraindividual analysis, the experience sampling method (ESM; Csikszentmihalyi \& Larson, 1987; Hektner et al., 2007) was used to assess goals and emotions multiple times within each student in regular classroom settings in the same subject domains. To make sure that our results were not mere epiphenomena of other variables, we controlled for students' sex, age, academic achievement, and the respective subject domain in all analyses.

\section{Method}

\subsection{Sample and Procedure}

The sample consisted of $N=120$ Swiss $10^{\text {th }}$ grade students $(37 \%$ female; mean age $=$ 15.61 years, $S D=0.59$ ). Participants were randomly selected from 35 classrooms (two to four students from each classroom) from seven upper-track schools (Gymnasium) in the Germanspeaking parts of Switzerland. There were, on average, 19.8 students (56\% female) in each classroom, and the student composition of classrooms was the same across the four subject domains considered in our study (mathematics, German, English, and French). Students were instructed by different teachers across those four subject domains.

The procedure included the following steps. First, in their classrooms, students completed a paper-and-pencil questionnaire focusing on demographic information. Second, ESM data were collected for a period of ten school days in the second term of the academic year using handheld devices (iPod Touch 4G; experience-sampling-software: iDialog Pad; Kubiak \& Krog, 2012). Participants were asked to use the handheld device to record their current goals and immediate emotional experiences in their mathematics, German, English, and French classes.

Students were instructed to activate their handheld devices at the beginning of their classes; each class lasted 45 minutes. After activating the device, students were asked to indicate the subject of the class. Subsequently, the device randomly emitted one audible signal during 
class time indicating that a digital questionnaire was available for students to immediately complete.

The device displayed one question at a time. Items were designed to assess achievement goals and achievement emotions. Within the two blocks assessing goals and emotions, items were presented in an order that was completely randomized across assessments and students. In total, 1,779 questionnaires were initiated and a total of 1,409 (79\%) questionnaires were completed. The reasons that were indicated for not completing the questionnaire were the following: taking a test $(51 \%)$; performing other priority tasks (25\%); not attending class because the teacher was absent (17\%); the presence of a different teacher than usual (7\%). On average, each student completed 11.74 questionnaires throughout the ten days $(S D=5.32$; minimum $=1$, maximum $=$ 26). On average, $3.55,2.54,2.89$, and 2.75 of the questionnaires were related to mathematics, German, English, and French, respectively.

Third, immediately after the ten state-assessment days, students completed a paper-andpencil questionnaire assessing their trait achievement goals and emotions. We assessed these variables after the state assessment because the state reports were the most important variables in our study; we wanted to avoid any influence of the trait assessment on the state reports. After the trait assessment, students returned the handheld devices to the testing personnel.

\subsection{Study Measures}

In line with principles of ESM methodology (Hektner et al., 2007), state goals and emotions were assessed using single-item measures. Although multi-item measures may be more reliable, such measures take more time to complete than single-item measures and could severely compromise the validity of state assessments. More specifically, when participants are asked to report about state goals and emotions, longer self-report measures could negatively influence participants' responses by providing more time to reflect and prompting recall biases. In addition, 
by requiring more time to respond, multi-item scales might end up assessing participants' emotional response to completing the questionnaire, rather than their emotions concerning the classroom activity that they are currently engaged in. For these reasons, single-item state measures are deemed appropriate for use in ESM studies (for other ESM emotion studies using single item measures, see e.g., Nett, Goetz, \& Hall, 2011; Tong et al., 2007).

The reliability and validity of single-item measures has been supported by findings from Wanous, Reichers, and Hudy (1997) and a recent analysis by Gogol et al. (2014) focusing on motivational and emotional constructs in education. We investigated the reliability of the singleitem measures used in the present study by computing $\operatorname{ICC}(2)$ for the state variables and by correlating trait scores and aggregated state scores. Results of these analyses are outlined in the Appendix and indicate that the single-item measures were indeed reliable.

2.2.1 Achievement goals. The goals of the trichotomous achievement goal model were assessed with slightly adapted items from Elliot and McGregor's (2001) Achievement Goal Questionnaire (AGQ). In both the trait and state assessments, participants responded on a 5-point Likert-type scale $(1=$ strongly disagree to $5=$ strongly agree $)$. In the trait assessment, the three goals were each assessed with respect to the domains of mathematics, German, English, and French. The items were as follows: "My goal in [DOMAIN] is to learn as much as possible" (mastery goal), "My goal in [DOMAIN] is to perform better than the other students" (performance-approach goal), and "My goal in [DOMAIN] is to avoid performing poorly compared to others" (performance-avoidance goal). The items for the state assessment were "My goal at this moment is to learn as much as possible" (mastery goal), "My goal at this moment is to perform better than the other students" (performance-approach goal), and "My goal at this moment is to avoid performing poorly compared to others" (performance-avoidance goal). 
2.2.2 Achievement emotions. In both the trait and state assessments, we measured students' enjoyment, pride, anxiety, shame, anger, and boredom. Participants responded using a five-point Likert-type scale $(1=$ not at all to $5=$ very strongly $)$. The trait emotions were assessed with respect to the domains of mathematics, German, English, and French using the following item format: "In [DOMAIN] classes I usually experience [EMOTION]". A parallel wording was used for the items in the state assessment, similar to previous state assessments in the classroom context (e.g., Goetz, Bieg, Lüdtke, Pekrun, \& Hall, 2013). The intensity of each of the six emotions was assessed with the item "At this moment I am experiencing [EMOTION]".

2.2.3 Covariates: Sex, age, academic achievement, and school subject. To ensure that any observed relations were not mere artifacts of other plausible variables, we assessed and controlled for sex, age, academic achievement, and school subject in our analyses. These variables were included because they have been shown to influence students' emotions (for sex, see e.g., Frenzel, Pekrun, \& Goetz, Frenzel, Pekrun, Hall, \& Lüdtke, 2007; for age, academic achievement, and school subject, see Goetz et al., 2007). Students' sex and age were assessed via self-report. School subject was also assessed from students' self-report. Academic achievement was assessed in terms of students' midyear grades (i.e., the last grades obtained before the present study) in mathematics, German, English, and French, which were obtained from the school administration. In the Swiss school system, there are two terms in the school year; midyear grades reflect students' achievement before the data assessment of the present study, which was conducted in the second term. Academic achievement was included as a covariate in order to control for the effect of this source of achievement feedback on academic emotions. Grades ranged from 1 (poor) to 6 (excellent).

\subsection{Data Analysis}

The data were used to examine the interindividual and intraindividual relations between 
the three goals and the six emotions. For the interindividual analyses, the trait assessments of goals and emotions were used. For each of the six emotions, a multiple regression equation was modeled, with the three goals included as predictors. As the trait data were available for four different subjects, these regression analyses were based on 480 cases ( 120 students $\times 4$ domains). Thus, observations were nested within school subjects, with school subjects representing a fixed rather than a random factor. In line with previous research dealing with such a data structure (e.g., Huang, 2014; Möhring, 2012), we controlled for the effects of the subject domain by including dummy variables, namely three variables representing the four domains (German, English, French, and mathematics as the reference domain; Goldstein, 2010; e.g., dummy variable 1: German $=1$, other domains $=0$ ). In addition to the subject domain, we controlled for sex, age, and academic achievement by also including them as covariates.

For the intraindividual analyses, the state assessments of goals and emotions were used. For each of the six state emotions, a multilevel multiple regression equation was modeled to examine the predictive value of the three state goals. The data of the state assessment (i.e., ESM) had a two-level structure, with points of time for the ESM assessments (Level 1; total $N=1,409$ assessments) nested within persons (Level 2; $N=120$ ). In order to account for clustering in the state data (ESM assessments within persons), we used multilevel modeling with Mplus 7.11 (Muthén \& Muthén, 1998-2012). Similar to the interindividual analyses, we included three dummy variables accounting for the four school subjects (mathematics as reference domain) at Level 1 to take the effects of the subject domain into account. At Level 1, we included state goals as well as the three dummy variables accounting for the subject domains as predictors of state achievement emotions. At Level 2 (person level), sex, age, and academic achievement in the four subject domains were included as covariates. Each of the multiple regression models was structured as a random intercepts and slopes model with predictors of state emotions on level 1 
and predictors of the intercepts on level 2 (intercepts as outcomes model).

\section{Results}

\subsection{Preliminary Analysis}

Table 1 provides the means and standard deviations for the study variables. For state achievement goals and emotions, the values are based on person-aggregated scores. For all variables, the values are reported separately for the domains of mathematics, German, English and French.

Table 2 shows variance components and intra-class correlations (ICCs) for the state assessment. The two-level models reflect the structure of assessments nested within persons. The ICCs for achievement goals and achievement emotions are similar in magnitude (ICCs range from .257 to .332 for goals, and from .204 to .325 for emotions). Thus, most of the variance in both constructs originated from situational variation within persons.

Table 3 shows the correlations between trait achievement goals and trait achievement emotions. These correlations are based on person values which represent the mean level of each construct across the four domains.

Table 4 shows the correlations between state achievement goals and state achievement emotions, based on a two-level model without predictors (null-model) and with assessments nested within persons. As such, the correlations at Level 1 are based on the intraindividual distributions of variables, and the correlations at Level 2 are based on the interindividual distributions of variables. The Level 1 correlations show whether a higher score on a variable in a given situation is associated with a higher score on the other variable in the same situation. The Level 2 correlations show the between-person correlations between the aggregated state variables. Thus, they show whether persons having higher scores on one variable also have higher scores on the other variable across situations. 
At Level 1, the correlations ranged from $|.30|$ to $|.48|$ for achievement goals and from $|.01|$ to $|.51|$ for achievement emotions. The correlations between achievement goals and achievement emotions ranged from $|.02|$ to $|.28|$. At Level 2, the correlations ranged from $|.36|$ to $|.90|$ for achievement goals and from $|.08|$ to $|.94|$ for achievement emotions. The correlations between goals and emotions ranged from $|.08|$ to $|.58|$. As noted, the level 1 and level 2 correlations are statistically independent from each other as they refer to different distributions (within vs. between persons), and some of the correlations do in fact show substantial differences across the two levels (e.g., the correlations between performance-approach and performance-avoidance goals).

\subsection{Main Analyses}

3.2.1 Interindividual analysis (trait assessment). Table 5 shows the results of the multiple regression analyses for each of the six trait emotions including the three trait goals as predictors. The results are in line with our theoretical expectations. Mastery goals were positive predictors of enjoyment $(b=0.40, p<.001)$, and negative predictors of anger $(b=-0.31, p<$ $.001)$ and boredom $(b=-0.40, p<.001)$. Performance-approach goals were positive predictors of pride $(b=0.44, p<.001)$, and performance-avoidance goals were positive predictors of anxiety ( $b=0.15, p<.01)$ and shame $(b=0.10, p<.05)$. In addition to these expected relations, mastery goals positively predicted pride $(b=0.12, p<.01)$. Further, performance-approach goals positively predicted enjoyment $(b=0.23, p<.01)$, and performance-avoidance goals positively predicted anger $(b=0.22, p<.05)$.

We also found a number of significant effects of the covariates. Age was a positive predictor of pride. Mathematics and German achievement positively predicted enjoyment, and English achievement positively predicted pride and boredom. With respect to the school subjects, as compared to mathematics, students reported higher levels of enjoyment in German and 
English, lower levels of anxiety and anger in German and English, and lower shame in German.

3.2.2 Intraindividual analyses (state assessment). Table 6 shows the results of the multilevel multiple regression analyses for each of the six state emotions with the three state goals as predictors. For the relations proposed by the Pekrun et al. (2006, 2009) model, the results were fully consistent with the interindividual findings. Mastery goals were positive predictors of enjoyment $(b=0.22, p<.001)$, and negative predictors of anger $(b=-0.12, p<.01)$ and boredom $(b=-0.29, p<.001)$. Performance-approach goals were positive predictors of pride $(b=0.18, p<$ $.001)$, and performance-avoidance goals were positive predictors of anxiety $(b=0.10, p<.05)$ and shame $(b=0.07, p<.05)$. In addition to these expected relations, mastery goals positively predicted pride $(b=0.15, p<.001)$. Further, performance-approach goals positively predicted enjoyment $(b=0.13, p<.01)$ and shame $(b=0.07, p<.05)$.

Again, there also were a number of significant effects of the covariates. Males reported higher levels of enjoyment. Further, mathematics achievement negatively predicted anger. Finally, as compared to mathematics, students experienced higher levels of enjoyment and lower levels of anxiety, shame, and anger in German and English.

\section{Discussion}

This research examined whether theoretical propositions on the relations between achievement goals and achievement emotions, as outlined by Pekrun and colleagues (2006, 2009), are supported when adopting an intraindividual empirical approach. Although findings of previous studies were largely in line with these propositions (for reviews see Huang, 2011; Linnenbrink-Garcia \& Barger, 2014), they were based on interindividual analyses and failed to examine the intraindividual relations of achievement goals and emotions. This limitation is crucial, as interindividual findings cannot provide support for models that actually address the 
intraindividual mechanisms linking goals and emotions (Linnnenbrink \& Pintrich, 2002; Pekrun et al., 2006, 2009).

\subsection{Intraindividual versus Interindividual Relations between Achievement Goals and}

\section{Achievement Emotions}

4.1.1 Correlational analysis. The present study examined three types of correlations between achievement goals and emotions: (a) interindividual correlations between trait goals and trait emotions, (b) interindividual correlations between aggregated state goals and state emotions (Level 2 in multi-level analysis), and (c) intraindividual correlations of these goals and emotions (Level 1 in multi-level analysis). The interindividual correlations at the trait level (Table 3) and at the person level using aggregated state data (Table 4) were equivalent, indicating that the aggregated state data behaved in similar ways as the trait data. By contrast, some of the intraindividual correlations differed from these interindividual correlations.

Specifically, performance-approach and performance-avoidance goals were clearly separated at the intraindividual level $(r=.48)$, in contrast to their strong correlation at the interindividual level ( $r \mathrm{~s}=.86$ and .90 for trait goals and aggregated state goals, respectively). This result is in line with findings by Rebar and Conroy (2013) who reported that intraindividual correlations among achievement goals ranged from -.06 to .61, whereas interindividual correlations ranged from .75 to .96 . Similarly, achievement emotions were more clearly separated at the intraindividual level. For example, the intraindividual correlation between state anxiety and state shame was $r=.51$ (Table 4), whereas the interindividual correlations were $r$ s $=.80$ and .94 (for trait emotions and aggregated state emotions, respectively; Tables 3 and 4).

A possible explanation for these striking differences in the size of correlations is that individual differences in response biases, such as the tendency to agree to self-report items, might boost interindividual correlations, but do not play as much of a role in intraindividual 
correlations. Furthermore, the strength of relations between variables may depend on the situational specificity of the assessment, with state assessments being more specific than trait assessments. Within a given situation, specific emotions (e.g., boredom) may co-occur with various different levels of another emotion (e.g., anger), depending on the specifics of the situation. For example, in some situations boredom may be high and anger low, whereas in other situations, both may be high. Accordingly, correlations between these emotions across situations may be low. In contrast, interindividual relations between trait variables are based on (mentally) averaged recollections across situations, which may boost relations between these variables.

4.1.2 Interindividual regression analysis: Replicating previous findings. Our results on the interindividual relations between achievement goals and achievement emotions were in line with the results of previous studies (for reviews see Huang, 2011; Linnenbrink-Garcia \& Barger, 2014) and proved to be robust when controlling for students' sex, age, and academic achievement, as well as the subject domain in which the constructs were assessed. Specifically, mastery goals were a predictor of activity emotions (positive for enjoyment, negative for boredom and anger; for similar results see e.g., Daniels et al, 2008, 2009; King, McInerney, \& Watkins, 2012; Shih, 2008), and performance-based goals were a positive predictor of outcome emotions (performance-approach goals for pride, and performance-avoidance goals for anxiety and shame; for similar results see e.g., King et al., 2012). In sum, the results of the interindividual regression analyses replicated previous findings and supported the theoretical predictions.

Moreover, beyond these expected links, we found three additional relations which have also been reported in previous studies (Linnenbrink-Garcia \& Barger, 2014). First, mastery goals positively predicted pride (for similar results see e.g., King et al., 2012; Pekrun et al., 2006, 2009). It might be that students not only focus on achievement activities per se when oriented toward mastery goals, but also think about possible positive outcomes of gaining mastery, which 
might facilitate pride. Second, performance-approach goals positively predicted enjoyment (for similar results see e.g., Daniels et al, 2008, 2009; King et al., 2012). This result indicates that performance-approach goals might focus attention not only on the outcomes of the learning process, but also on the learning process itself, with progress toward the goal sparking enjoyment (Linnenbrink \& Pintrich, 2002). Finally, performance-avoidance goals positively predicted anger (for similar results see e.g., Pekrun et al., 2009), which might be explained by the "aversive nature of task engagement during avoidance goal pursuit” (Pekrun et al., 2009, p. 129).

4.1.3 Intraindividual multi-level regression analysis. Our results on the intraindividual relations between achievement goals and achievement emotions were equivalent with the results of the interindividual analysis: Mastery goals were a positive predictor of enjoyment and a negative predictor of boredom and anger; performance-approach goals were a positive predictor of pride; and performance-avoidance goals were a positive predictor of anxiety and shame. In sum, findings from the intraindividual analysis directly support the propositions of the Pekrun et al. (2006, 2009) model and complement previous interindividual findings.

Again, we found a few additional associations. In line with the interindividual findings, mastery goals positively predicted pride, and performance-approach goals positively predicted enjoyment. Additionally, performance-approach goals positively predicted shame (for similar results see e.g., King et al., 2012; Pekrun et al., 2006). As argued by Linnenbrink-Garcia and Barger (2014), performance-approach goals, given their focus on being competent relative to others, focus attention on the self, and shame is an emotion that, likewise, implicates the self. As such, students with high levels of performance-approach goals might be prone to experience not only positive self-related achievement emotions like pride, but also negative self-related emotions like shame. However, it is important to note that the relation between performance-approach goals and shame, although reaching significance, was weak. 
4.1.4 Equivalence of interindividual and intraindividual relations. As noted, inter- and intraindividual relations between variables are statistically independent (e.g., Schmitz \& Skinner, 1993; for the independence of relations across higher levels of aggregation, see Robinson, 1950). The psychological mechanisms thought to link achievement goals and achievement emotions pertain to intraindividual processes, as addressed in current models of the achievement goalemotion link (Linnenbrink \& Pintrich, 2002; Pekrun et al., 2006, 2009). From this perspective, the empirical support for the proposed intraindividual links between achievement goals and emotions that is provided by the current study is of pivotal importance for validating these models.

It is less obvious why many of the interindividual relations between achievement goals and emotions, as documented in previous research as well as the present study, are the same as these intraindividual relations. Given the multitude of factors that can render interindividual and intraindividual relations non-equivalent (see Voelkle et al., 2014), why should the interindividual and intraindividual relations between achievement goals and emotions show convergence? For example, why should mastery goals not only positively predict higher state enjoyment in a given situation, but also predict students' ongoing enjoyment across time and situations?

We believe that there are sound reasons to assume that interindividual and intraindividual relations between psychological variables often coincide. Specifically, it can be assumed that interindividual relations between variables often result from the repeated occurrence of the respective intraindividual functional effects (Fleeson, 2001; Fleeson \& Gallagher, 2009). For example, let us assume that individual trait mastery goals promote activation of situational mastery goals in academic settings, and that these situational goals, in turn, facilitate students' enjoyment of learning. Over time, repeated activation of situational mastery goals and their positive influence on enjoyment would imply that both students' trait mastery goals and their trait 
enjoyment of learning (i.e., habitual enjoyment) are strengthened. By contrast, students low in trait mastery goals would be less likely to endorse state mastery goals, and would experience enjoyment less frequently. As such, the positive intraindividual effects of state mastery goals on state emotion would translate into a positive interindividual relation between trait mastery goals and trait enjoyment. Overall, such an equivalence of interindividual and intraindividual relations may be more typical for psychological functioning than instances in which the two diverge.

\subsection{Study Limitations}

Some limitations of the present study should be noted and can be used to suggest directions for future research. First, we assessed only a restricted number of achievement goals (three, based on the trichotomous achievement goal framework) and achievement emotions (six) in our study. Using ESM within regular lessons did not allow including more goals and emotions, due to the need to keep interruption of lessons to a minimum (and to obtain approval for the study procedure). Although the achievement goals and achievement emotions assessed in our study are those endorsed most frequently by high school students, future studies would do well to include a broader variety of achievement goals (e.g., $2 \times 2,3 \times 2$, potential-based; Elliot $\&$ McGegor, 2001; Elliot, Murayama, Kobeisy, \& Lichtenfeld, in press; Elliot et al., 2011) and achievement emotions (e.g., social achievement emotions like admiration, envy, or contempt; Pekrun \& Stephens, 2012).

Second, both achievement goals and emotions were obtained from students' self-reports, which might have resulted in some amount of common method bias (although we controlled for important confounding, objective variables including sex, age, achievement, and subject domain; Podsakoff, MacKenzie, Lee, \& Podsakoff, 2003). To more fully control for such possible bias, future studies might use additional data sources like physiological indicators and behavioral observation to assess students' emotions (e.g., measuring students' emotion via behavioral 
indicators of facial or postural expression).

Furthermore, although we controlled for important confounding variables, it cannot be completely ruled out that other variables had an impact on the observed relations between achievement goals and emotions. Thus, future studies might control for additional confounding variables such as students' interest in the course subject which may influence both their mastery goal focus and their enjoyment.

Finally, the ESM approach that we used for jointly examining inter- and intraindividual relations does not allow one to derive conclusions on the causal ordering of variables. Given that we collected data during lessons and across different school subjects, our state data were not equidistant in nature. The number of lessons differed across weeks and subjects, and different subjects were taught on different days during the week and at different time points during the day. As such, it was not possible to use the data for an analysis of causal relationships (e.g., cross-lagged analysis). Future studies should focus on examining the causal links between state goals and emotions by using equidistant assessments (e.g., by using diaries with daily measures; e.g., Krejtz, Nezlek, Michnicka, Holas, \& Rusanowska, 2014).

From a theoretical perspective, in the model developed by Pekrun et al. $(2006,2009)$ goals are posited to influence students' emotions. However, it may also be that emotions influence students' achievement goal adoption. To the extent that both causal directions are operative, achievement goals and achievement emotions could be linked by reciprocal causation over time (Linnenbrink \& Pintrich, 2002; also see Linnenbrink-Garcia \& Barger, 2014; Pekrun, 2006). With respect to possible classroom interventions, reciprocal causality would imply that it may be optimal to target both goals and emotions in interventions, as either variable might have a positive influence on the other. Promoting one of the two variables might be the starting point of self-enhancing processes (e.g., an upward spiral of mastery goals enhancing enjoyment and vice 
versa). Similar to research on the reciprocal causal links between academic self-concept and achievement (e.g., Marsh \& Martin, 2011), experimental research (e.g., Pekrun, Cusack, Murayama, Elliot, \& Thomas, 2014) and longitudinal studies are needed to disentangle the causal effects that underlie the observed relations between achievement goals and achievement emotions.

\subsection{Conclusion}

The present study is the first investigation examining the link between students' achievement goals and their achievement emotions using a combined interindividual and intraindividual analysis. Based on an assessment of students' trait and state achievement goals and emotions in a real-life classroom context, the findings confirm that achievement goals and emotions are closely related. More specifically, they support propositions of Pekrun et al.'s (2006, 2009) model in showing that mastery goals relate to students' activity emotions (positive to enjoyment, negative to boredom and anger), and that performance-based goals relate to students' outcome emotions (performance-approach goals positively related to pride, performance-avoidance goals positively related to anxiety and shame). These findings were robust across different sets of interindividual and intraindividual analyses, indicating that interindividual versus intraindividual relations between achievement goals and emotions are likely to be equivalent.

This is an encouraging finding for both theory development and educational practice. As aptly argued by Voelkle et al. (2014), findings on the intraindividual level are a prerequisite to support theoretical assumptions on intraindividual functioning and to develop intervention programs for individuals. For example, although previous findings have shown a positive relation between mastery goals and enjoyment at the interindividual level, these findings are not sufficient to justify investing effort in treatment interventions that aim to enhance students' enjoyment by 
fostering their mastery goals. However, the present study indicates that this relation also holds at the intraindividual level. As such, the present findings do encourage the development of classroom practices and treatment interventions that foster students' adaptive emotions and reduce their maladaptive emotions by changing their goal foci. For example, future studies might investigate whether teachers' displays of enthusiasm (Keller, Goetz, Hensley, Becker, \& Morger, 2014) can foster students' mastery goal adoption and, consequently, enhance students' enjoyment and reduce their boredom and anger in the classroom and beyond (e.g., when doing homework assignments). Similarly, positive feedback on mastery and performance might foster students' mastery and performance-approach goals which in turn can be assumed to increase students' positive emotions such as hope for success and enjoyment of learning. 


\section{References}

Bong, M. (2009). Age-related differences in achievement goal differentiation. Journal of Educational Psychology, 101, 879-896.

Brillat-Savarin, A. (1999). The physiology of taste: Or, meditations on transcendental gastronomy (M. F. K. Fisher, Trans.). Washington, DC: Counterpoint.

Csikszentmihalyi, M., \& Larson, R. (1987). Validity and reliability of the Experience-Sampling Method. Journal of Nervous and Mental Diseases, 9, 526-536.

Daniels, L. M., Haynes, T. L., Stupnisky, R. H., Perry, R. P., Newall, N. E., \& Pekrun, R. (2008). Individual differences in achievement goals: A longitudinal study of cognitive, emotional, and achievement outcomes. Contemporary Educational Psychology, 33, 584-608.

Daniels, L. M., Stupnisky, R. H., Pekrun, R., Haynes, T. L., Perry, R. P., \& Newall, N. E. (2009). A longitudinal analysis of achievement goals: From affective antecedents to emotional effects and achievement outcomes. Journal of Educational Psychology, 101, 948-963. doi:10.1037/a0016096

Duchesne, S., \& Ratelle, C. (2010). Parental behaviors and adolescents' achievement goals at the beginning of middle school: Emotional problems as potential mediators. Journal of Educational Psychology, 102, 497-507.

Elliot, A. J., \& Harackiewicz, J. M. (1996). Approach and avoidance achievement goals and intrinsic motivation: A mediational analysis. Journal of Personality and Social Psychology, 70, 461-475.

Elliot, A. J., \& McGregor, H. A. (2001). A 2 x 2 achievement goal framework. Journal of Personality and Social Psychology, 80, 501-519. doi:10.1O37//OO22-3514.80.3.501

Elliot, A. J., Murayama, K., Kobeisy, A., \& Lichtenfeld, S. (in press). Potential-based achievement goals. British Journal of Educational Psychology. 
Elliot, A. J., Murayama, K., \& Pekrun, R. (2011). A 3 x 2 achievement goal model. Journal of Educational Psychology, 103, 632-648. doi:10.1037/a0023952

Fleeson, W. (2001). Towards a structure- and process-integrated view of personality: Traits as density distributions of states. Journal of Personality and Social Psychology, 80, 10111027. doi:10.1037/0022-3514.80.6.1011

Fleeson, W., \& Gallagher, P. (2009). The implications of big-five standing for the distribution of trait manifestation in behavior: Fifteen experience-sampling studies and a meta-analysis. Journal of Personality and Social Psychology, 97, 1097-1114. doi:10.1037/a0016786

Frenzel, A. C., Pekrun, R., \& Goetz, T. (2007). Girls and mathematics - A "hopeless" issue? A control-value approach to gender differences in emotions towards mathematics. European Journal of Psychology of Education, 22(4), 497-514.

Goetz, T., Bieg, M., Lüdtke, O., Pekrun, R., \& Hall, N. C. (2013). Do girls really experience more anxiety in mathematics? Psychological Science, 24, 2079-2087. doi:10.1177/0956797613486989

Goetz, T., Frenzel, C. A., Pekrun, R., Hall, N. C., \& Lüdtke, O. (2007). Between- and withindomain relations of students' academic emotions. Journal of Educational Psychology, 99(4), 715-733.

Gogol, K., Brunner, M., Goetz, T., Martin, R., Ugen, S., Fischbach, A., Keller, U., \& Preckel, F. (2014). 'My questionnaire is too long!' The assessments of motivational-affective constructs with three-item and single-item measures. Contemporary Educational Psychology, 39, 188-205. doi:10.1016/j.cedpsych.2014.04.002

Goldstein, H. (2010). Multilevel statistical models (4th edition). Chichester, UK, John Wiley \& Sons. 
Hektner, J. M., Schmidt, J. A., \& Csikszentmihalyi, M. (2007). Experience sampling method: Measuring the quality of everyday life. Thousand Oaks, CA: Sage Publications, Inc. Retrieved from EBSCOhost.

Huang, C. (2011). Achievement goals and achievement emotions: A meta-analysis. Educational Psychology Review, 23(3), 359-388.

Huang, F. L. (2014). Alternatives to multilevel modeling for the analysis of clustered data. The Journal of Experimental Education. doi:10.1080/00220973.2014.952397

Keller, M. M., Goetz, T., Hensley, L., Becker, E. S., \& Morger, V. (2014). Feeling and showing: A new conceptualization of dispositional teacher enthusiasm and its relation to students' interest. Learning and Instruction, 33, 29-38.

King, R. B., McInerney, D. M., \& Watkins, D. A. (2012). How you think about your intelligence determines how you feel in school: The role of theories of intelligence on academic emotions. Learning and Individual Differences, 22, 814-819.

Krejtz, I., Nezlek, J. B., Michnicka, A., Holas, P., \& Rusanowska, M. (2014). Counting one's blessings can reduce the impact of daily stress. Journal of Happiness Studies, doi:10.1007/s10902-014-9578-4.

Kubiak, T., \& Krog, K. (2012). Computerized sampling of experiences and behavior. In M. R. Mehl, \& T. S. Conner (Eds.), Handbook of research methods for studying daily life (pp. 124-143). New York: Guilford.

Linnenbrink, E. A., \& Pintrich, P. R. (2002). Achievement goal theory and affect: An asymmetrical bidirectional model. Educational Psychologist, 37, 69-78. doi:10.1207/S15326985EP3702_2

Linnenbrink-Garcia, L., \& Barger, M. M. (2014). Achievement goals and emotions. In R. Pekrun \& L. Linnenbrink-Garcia (Eds.), International handbook of emotions in education (pp. 
142-161). New York, NY: Routledge.

Lüdtke, O., Trautwein, U., Kunter, M., \& Baumert, J. (2007). Reliability and agreement of student ratings of the classroom environment: A reanalysis of TIMSS data. Learning Environments Research, 9(3), 215-230. doi:10.1007/s10984-006-9014-8

Marsh, H., \& Martin, A. J. (2011). Academic self-concept and academic achievement: Relations and causal ordering. British Journal of Educational Psychology, 81, 59-77.

Möhring, K. (2012).The fixed effects approach as an alternative to multilevel analysis for crossnational analyses, WP 16/2012, GK SOCLIFE Working Paper Series, URL: http://www.soclife.unikoeln.de/fileadmin/wiso_fak/gk_soclife/pdf/Working_papers/KMoehring_2012a_ssrn_the _fixed_effects.pdf.

Molenaar, P. C. M. (2004). A manifesto on psychology as idiographic science: Bringing the person back into scientific psychology, this time forever. Measurement, 2, 201-218. doi:10.1207/s15366359mea0204_1

Molenaar, P. C. M., \& Campbell, C. G. (2009). The new person-specific paradigm in psychology. Current Directions in Psychological Science, 18, 112-117. doi:10.1111/j.14678721.2009.01619.x

Muthén, L. K., \& Muthén, B. O. (1998-2012). Mplus User’s Guide. Seventh Edition. Los Angeles, CA: Muthén \& Muthén.

Nett, U. E., Goetz, T., \& Hall, N. C. (2011). Coping with boredom in school: An experience sampling perspective. Contemporary Educational Psychology, 36, 49-59. doi:10.1016/j.cedpsych.2010.10.003

Pekrun, R. (2006). The control-value theory of achievement emotions: Assumptions, corollaries, and implications for educational research and practice. Educational Psychology Review, 
18, 315-341. doi:10.1007/s10648-006-9029-9

Pekrun, R., Cusack, A., Murayama, K., Elliot, A. J., \& Thomas, K. (2014). The power of anticipated feedback: Effects on students' achievement goals and achievement emotions. Learning and Instruction, 29, 115-124. doi:10.1016/j.learninstruc.2013.09.002

Pekrun, R., Elliot, A. J., \& Maier, M. A. (2006). Achievement goals and discrete achievement emotions: A theoretical model and prospective test. Journal of Educational Psychology, 98, 583-597. doi:10.1037/0022-0663.98.3.583

Pekrun, R., Elliot, A. J., \& Maier, M. A. (2009). Achievement goals and achievement emotions: Testing a model of their joint relations with academic performance. Journal of Educational Psychology, 101, 115-135. doi:10.1037/a0013383

Pekrun R. \& Linnenbrink-Garcia, L. (2014) (Eds.) International handbook of emotions in education. New York: Routledge.

Pekrun, R., \& Stephens, E. J. (2012). Academic emotions. In K. R. Harris, S. Graham, \& T. Urdan, S. Graham, J. M. Royer, \& M. Zeidner (Eds.), APA educational psychology handbook (Vol. 2, pp. 3-31). Washington, DC: American Psychological Association. doi: $10.1037 / 13274-001$

Podsakoff, P. M., MacKenzie, S. M., Lee, J., \& Podsakoff, N. P. (2003). Common method variance in behavioral research: A critical review of the literature and recommended remedies. Journal of Applied Psychology, 88, 879-903.

Putwain, D. W., \& Symes, W. (2012). Achievement goals as mediators of the relationship between competence beliefs and test anxiety. British Journal of Educational Psychology, $82,207-224$.

Rebar, A. L., \& Conroy, D. E. (2013). Experimentally manipulated achievement goal state fluctuations regulate self-conscious emotional responses to feedback. Sport, Exercise, And 
Performance Psychology, 2, 233-249. doi:10.1037/a0034645

Robinson, W. S. (1950). Ecological correlations and the behavior of individuals. American Sociological Review, 15, 351-356.

Schantz, L. H., \& Conroy, D. E. (2009). Achievement motivation and intraindividual affective variability during competence pursuits: A round of golf as a multilevel data structure. Journal of Research in Personality, 43, 472-481. doi:10.1016/j.jrp.2009.02.002

Schmitz, B. \& Skinner, E. A. (1993). Perceived control, effort, and academic performance: Interindividual, intraindividual, and multivariate time series analyses. Journal of Personality and Social Psychology, 64, 1010-1028. doi:10.1037/0022-3514.64.6.1010

Schmitz, B. (1987). Zeitreihenanalyse in der Psychologie: Verfahren zur Veraenderungsmessung und Prozessdiagnostik (Time series analysis in psychology: Methods for the measurement of change and process evaluation). Weinheim, Germany: Beltz.

Shih, S.-S. (2005). Role of achievement goals in children's learning in Taiwan. The Journal of Educational Research, 98, 310-319.

Shih, S.-S. (2008). The relation of self-determination and achievement goals to Taiwanese eighth graders' behavioral and emotional engagement in schoolwork. The Elementary School Journal, 108, 313-334.

Sideridis, G. D. (2008). The regulation of affect, anxiety, and stressful arousal from adopting mastery-avoidance goal orientations. Stress and Health, 24, 55-69.

Tong, E. M. W., Bishop, G. D., Enkelmann, H. C., Why, Y. P., Diong, S. M., Khader, M., et al. (2007). Emotion and appraisal: A study using ecological momentary assessment. Cognition and Emotion, 21, 1361-1381. doi:10.1080/02699930701202012

Voelkle, M. C., Brose, A., Schmiedek, F., \& Lindenberger, U. (2014). Towards a unified framework for the study of between-person and within-person structures: Building a 
bridge between two research paradigms. Multivariate Behavioral Research, 49, 193-213. doi:10.1080/00273171.2014.889593

Wanous, J. P., Reichers, A. E., \& Hudy, M. J. (1997). Overall job satisfaction: How good are single-item measures? Journal of Applied Psychology, 82, 247-252. doi:10.1037/00219010.82 .2 .247 


\section{Appendix: Reliability of the Single-item Measures}

We computed the reliability of the single-item measures that were used in the present study.

\section{State Assessment}

ICC(2) was computed, which is a form of intra-class correlation (ICC(1); proportion of variance at a given level). ICC(2) is a function of ICC(1) and the average number of observations within the clusters of a given level (Lüdtke, Trautwein, Kunter, \& Baumert, 2007). In the context of the present study, $\operatorname{ICC}(2)$ can be interpreted as a measure of the reliability of aggregated (i.e., mean) state scores (Lüdtke et al., 2007). Table A1 shows the ICC(2)s across subjects and for each subject separately. Overall, ICC(2)s ranged from .734 to .921. Therefore, the aggregated state scores show good reliability both across subjects and for subjects individually.

\section{Trait Assessment}

In order to match the trait assessments to the state assessments, we used slightly modified single items for the trait assessment. As opposed to the state assessments, the reliability of the trait assessments could not be examined in the context of the present study. However, we did compute the correlations between the trait scores and the aggregated state scores (within students) for each subject in order to examine the convergent validity between state and trait assessments. Table A2 shows that these correlations were found to be significant and to range from .26 to .71, with an average correlation of .45 . It can be assumed that if the trait assessments were unreliable, they would not correlate with the state assessments. Therefore, given the reliability of the aggregated state assessments (see Table A1) and the convergent validity between state and trait assessments, we conclude that there is at least some indication of reliability of the trait assessments in the present study. 
Table A1

Reliabilities (Intra-class Correlations - ICC(2)) of State Achievement Goals and State Achievement Emotions Across School Subjects and for each School Subject Separately

\begin{tabular}{lccccc}
\hline & \multicolumn{5}{c}{ Intra-Class Correlation ICC(2) } \\
\cline { 2 - 6 } & Total & Mathematics & German & English & French \\
\hline Achievement goals & & & & & \\
Mastery goals & .802 & .853 & .842 & .866 & .901 \\
Performance-approach goals & .850 & .898 & .820 & .892 & .892 \\
Performance-avoidance goals & .854 & .898 & .890 & .863 & .889 \\
Achievement emotions & & & & \\
Enjoyment & .773 & .835 & .801 & .830 & .844 \\
Pride & .850 & .888 & .847 & .846 & .875 \\
Anxiety & .764 & .855 & .766 & .734 & .802 \\
Shame & .788 & .881 & .858 & .742 & .846 \\
Anger & .751 & .851 & .752 & .848 & .781 \\
Boredom & .802 & .900 & .827 & .921 & .817 \\
\hline
\end{tabular}

Note. ICC $(2)=$ Reliability of the mean score of the state scores of one student. $N_{\text {Level } 1}=1,409$ (assessments within students), $N_{\text {Level } 2}=120$ (students). 
Table A2

Correlations Between Trait Scores and Aggregated (mean) State Scores of Achievement Goals and Achievement Emotions Scores for Each School Subject

\begin{tabular}{|c|c|c|c|c|}
\hline & \multicolumn{4}{|c|}{ School Subject } \\
\hline & Mathematics & German & English & French \\
\hline \multicolumn{5}{|l|}{ Achievement goals } \\
\hline Mastery goals & $.37^{* * *}$ & $.51^{* * *}$ & $.38^{* * *}$ & $.51^{* * *}$ \\
\hline Performance-approach goals & $.52^{* * *}$ & $.45^{* * *}$ & $.48^{* * *}$ & $.61^{* * *}$ \\
\hline Performance-avoidance goals & $.53^{* * *}$ & $.55^{* * *}$ & $.52^{* * *}$ & $.71^{* * *}$ \\
\hline \multicolumn{5}{|l|}{ Achievement emotions } \\
\hline Enjoyment & $.34^{* * *}$ & $.42^{* * *}$ & $.31^{* * *}$ & $.34^{* * * *}$ \\
\hline Pride & $.51^{* * *}$ & $.57^{* * *}$ & $.39^{* * *}$ & $.44^{* * * *}$ \\
\hline Anxiety & $.45^{* * *}$ & $.45^{* * *}$ & $.26^{* *}$ & $.53^{* * *}$ \\
\hline Shame & $.26^{* *}$ & $.47^{* * *}$ & $.34^{* * *}$ & $.49^{* * *}$ \\
\hline Anger & $.34^{* * *}$ & $.46^{* * *}$ & $.26^{* *}$ & $.42^{* * *}$ \\
\hline Boredom & $.48^{* * * *}$ & $.59^{* * *}$ & $.26^{* *}$ & $.51^{* * * *}$ \\
\hline
\end{tabular}

Note. Only correlations between the same constructs are indicated (e.g., trait mastery goals with state mastery goals). $N=120$ (students).

$* * p<.01 . * * * p<.001$. 
Table 1

Descriptive Statistics for the Study Variables

\begin{tabular}{|c|c|c|c|c|c|c|c|c|}
\hline & \multicolumn{2}{|c|}{ Mathematics } & \multicolumn{2}{|c|}{ German } & \multicolumn{2}{|c|}{ English } & \multicolumn{2}{|c|}{ French } \\
\hline & $M$ & $S D$ & $M$ & $S D$ & $M$ & $S D$ & $M$ & $S D$ \\
\hline \multicolumn{9}{|l|}{ Achievement goals - trait } \\
\hline Mastery goals & 3.26 & 1.13 & 3.41 & 1.05 & 3.31 & 1.09 & 3.86 & 1.09 \\
\hline Performance-approach goals & 2.30 & 1.13 & 2.22 & 1.12 & 2.38 & 1.16 & 2.54 & 1.23 \\
\hline Performance-avoidance goals & 2.67 & 1.20 & 2.61 & 1.19 & 2.68 & 1.26 & 2.85 & 1.26 \\
\hline \multicolumn{9}{|l|}{ Achievement goals - state } \\
\hline Mastery goals & 3.17 & 0.89 & 3.00 & 0.98 & 2.79 & 0.93 & 3.12 & 0.94 \\
\hline Performance-approach goals & 2.27 & 0.84 & 2.28 & 0.93 & 2.19 & 0.92 & 2.31 & 0.90 \\
\hline Performance-avoidance goals & 2.66 & 0.91 & 2.66 & 1.04 & 2.37 & 1.01 & 2.65 & 0.95 \\
\hline \multicolumn{9}{|l|}{ Achievement emotions - trait } \\
\hline Enjoyment & 2.52 & 1.19 & 2.77 & 0.91 & 2.94 & 1.09 & 3.21 & 1.04 \\
\hline Pride & 2.07 & 1.10 & 2.26 & 1.03 & 2.17 & 1.11 & 2.39 & 1.16 \\
\hline Anxiety & 1.68 & 1.06 & 1.68 & 1.02 & 1.32 & 0.74 & 1.27 & 0.63 \\
\hline Shame & 1.56 & 0.90 & 1.45 & 0.71 & 1.35 & 0.73 & 1.36 & 0.69 \\
\hline Anger & 2.35 & 1.17 & 2.23 & 1.08 & 1.77 & 1.00 & 1.74 & 0.96 \\
\hline Boredom & 2.78 & 1.16 & 2.83 & 0.97 & 2.90 & 1.20 & 2.54 & 1.09 \\
\hline \multicolumn{9}{|l|}{ Achievement emotions - state } \\
\hline Enjoyment & 2.70 & 0.88 & 2.71 & 0.91 & 2.81 & 0.88 & 2.92 & 0.83 \\
\hline Pride & 2.10 & 0.99 & 2.03 & 0.88 & 2.07 & 0.92 & 2.10 & 0.89 \\
\hline Anxiety & 1.72 & 1.01 & 1.62 & 0.90 & 1.42 & 0.67 & 1.38 & 0.62 \\
\hline Shame & 1.66 & 0.90 & 1.53 & 0.81 & 1.32 & 0.56 & 1.42 & 0.65 \\
\hline Anger & 2.21 & 1.03 & 2.07 & 0.98 & 1.79 & 0.83 & 1.82 & 0.85 \\
\hline Boredom & 2.52 & 0.95 & 2.54 & 0.91 & 2.52 & 1.04 & 2.48 & 1.04 \\
\hline Academic achievement & 4.44 & 0.77 & 4.47 & 0.93 & 4.69 & 0.54 & 4.64 & 0.60 \\
\hline
\end{tabular}

Note. For the state variables, mean values and standard deviations are based on personaggregated scores. $N=120$ students; $N=1,409$ state assessments within students. 
Table 2

Variance Components and Intra-class Correlations (ICCs) for State Achievement Goals and State Achievement Emotions

$$
\text { Variance Level } 1 \text { - Situation Variance Level 2-Person ICC }
$$

\begin{tabular}{llll}
\hline Achievement goals & & & \\
Mastery goals & 1.009 & 0.350 & .257 \\
Performance-approach goals & 0.848 & 0.409 & .325 \\
Performance-avoidance goals & 0.962 & 0.479 & .332 \\
Achievement emotions & & & \\
Enjoyment & 1.021 & 0.297 & .225 \\
Pride & 0.897 & 0.431 & .325 \\
Anxiety & 0.800 & 0.221 & .216 \\
Shame & 0.596 & 0.189 & .240 \\
Anger & 1.096 & 0.281 & .204 \\
Boredom & 1.120 & 0.388 & .257 \\
\hline
\end{tabular}

Note. ICC: Variance on Level 2 divided by total variance. $N_{\text {Level 1 }}=1,409$ (assessments within

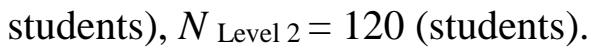


Table 3

Correlations Between Trait Achievement Goals and Trait Achievement Emotions

\begin{tabular}{|c|c|c|c|c|c|c|c|c|}
\hline & 1 & 2 & 3 & 4 & 5 & 6 & 7 & 8 \\
\hline $\begin{array}{l}1 \text { Mastery } \\
\text { goals }\end{array}$ & -- & & & & & & & \\
\hline $\begin{array}{l}2 \\
\text { Performance- } \\
\text { approach } \\
\text { goals }\end{array}$ & $.30^{* * * *}$ & -- & & & & & & \\
\hline $\begin{array}{l}3 \\
\text { Performance- } \\
\text { avoidance } \\
\text { goals }\end{array}$ & $.33^{* * * *}$ & $.86^{* * * *}$ & -- & & & & & \\
\hline 4 Enjoyment & $.53^{* * * *}$ & $.29^{* *}$ & $.30^{* *}$ & -- & & & & \\
\hline 5 Pride & $.22^{*}$ & $.46^{* * *}$ & $.40^{* * *}$ & $.42^{* * *}$ & -- & & & \\
\hline 6 Anxiety & -.01 & $.24^{*}$ & $.22^{*}$ & -.09 & $.18^{*}$ & -- & & \\
\hline 7 Shame & .02 & $.24^{*}$ & $.22^{*}$ & -.01 & $.24 * *$ & $.80^{* * * *}$ & -- & \\
\hline 8 Anger & $-.28^{* *}$ & $.19^{*}$ & $.19^{*}$ & $-.34^{* * * *}$ & $.18^{*}$ & $.51^{* * *}$ & $.42^{* * * *}$ & -- \\
\hline 9 Boredom & $-.38^{* * *}$ & -.06 & -.04 & $-.50^{* * *}$ & $.24^{* *}$ & $.27^{* * * *}$ & $.21^{*}$ & $.50^{* * *}$ \\
\hline
\end{tabular}

Note. Correlations are based on person values which represent the mean level of each construct across the four domains of mathematics, German, English, and French. $N=120$ (students).

$* p<.05 . * * p<.01 . * * * p<.001$. 
Table 4

Correlations Between Achievement Goals and Achievement Emotions of the State Assessment (Two-level Model)

\begin{tabular}{|c|c|c|c|c|c|c|c|c|c|}
\hline & 1 & 2 & 3 & 4 & 5 & 6 & 7 & 8 & 9 \\
\hline $\begin{array}{l}1 \text { Mastery } \\
\text { goals }\end{array}$ & -- & $.36^{* * *}$ & $.53^{* * *}$ & $.49^{* * *}$ & .23 & -.14 & -.14 & $-.40^{* * *}$ & $-.58^{* * *}$ \\
\hline $\begin{array}{l}2 \\
\text { Performanc } \\
\text { e-approach } \\
\text { goals }\end{array}$ & $.30^{* * *}$ & -- & $.90^{* * *}$ & $.23^{*}$ & $.31^{* *}$ & $.43^{* * *}$ & $.41^{* * * *}$ & $.35^{* *}$ & -.08 \\
\hline $\begin{array}{l}3 \\
\text { Performanc } \\
\text { e-avoidance } \\
\text { goals }\end{array}$ & $.32^{* * *}$ & $.48^{* * *}$ & -- & $.22^{*}$ & $.22^{*}$ & $.28^{*}$ & $.26^{*}$ & .22 & -.20 \\
\hline $\begin{array}{l}4 \\
\text { Enjoyment }\end{array}$ & $.24^{* * *}$ & $.28^{* * * *}$ & $.13^{* *}$ & -- & $.56^{* * *}$ & -.14 & .08 & $-.23^{*}$ & $-.32^{* *}$ \\
\hline 5 Pride & $.20^{* * *}$ & $.24^{* * *}$ & $.14^{* *}$ & $.41^{* * * *}$ & -- & $.26^{*}$ & $.39^{* *}$ & $.24^{*}$ & .15 \\
\hline 6 Anxiety & .03 & .02 & .09 & $-.14^{* * *}$ & -.02 & -- & $.94^{* * *}$ & $.71^{* * * *}$ & $.31^{* *}$ \\
\hline 7 Shame & .04 & .05 & $.09^{*}$ & $-.10^{* * *}$ & .01 & $.51^{* * * *}$ & -- & $.66^{* * *}$ & $.35^{* *}$ \\
\hline 8 Anger & -.06 & -.02 & .02 & $-.28^{* * *}$ & $-.09^{*}$ & $.35^{* * *}$ & $.40^{* * * *}$ & -- & $.57^{* * *}$ \\
\hline 9 Boredom & $-.28^{* * *}$ & $-.11^{* *}$ & -.04 & $-.24^{* * *}$ & $-.09^{*}$ & .08 & $.19^{* * * *}$ & $.26^{* * *}$ & -- \\
\hline
\end{tabular}

Note. Correlations above the diagonal are between person correlations (level 2, person);

correlations below the diagonal are within person correlations (level 1, situation). $N_{\text {Level } 1}=1,409$ (assessments within students), $N_{\text {Level } 2}=120$ (students).

$* p<.05 . * * p<.01 . * * * p<.001$. 
Table 5

Multiple Regression Analyses for Trait Achievement Goals as Predictors of Trait Achievement Emotions

\begin{tabular}{lcccccc}
\hline Predictor variable & Enjoyment & Pride & Anxiety & Shame & Anger & Boredom \\
\hline $\begin{array}{l}\text { Achievement goals } \\
\text { Mastery goals }\end{array}$ & $0.40^{* * *}$ & $0.12^{* *}$ & -0.04 & -0.07 & $-0.31^{* * *}$ & $-0.40^{* * *}$ \\
$\begin{array}{l}\text { Performance- } \\
\text { approach goals }\end{array}$ & $0.23^{* *}$ & $0.44^{* * *}$ & -0.04 & -0.02 & -0.04 & -0.06 \\
$\begin{array}{l}\text { Performance- } \\
\text { avoidance goals }\end{array}$ & -0.07 & -0.05 & $0.15^{* *}$ & $0.10^{*}$ & $0.22^{*}$ & 0.12 \\
Demographic & & & & & \\
Variables & & & & & \\
Sex & 0.10 & -0.08 & -0.12 & -0.14 & -0.03 & -0.13 \\
Age & -0.03 & $0.20^{*}$ & -0.04 & -0.04 & -0.03 & 0.12 \\
Academic & & & & & \\
achievement & & & & & & \\
Mathematics & $0.14^{*}$ & -0.07 & 0.04 & 0.05 & -0.02 & -0.06 \\
German & $0.21^{*}$ & -0.01 & -0.02 & 0.07 & 0.03 & -0.04 \\
English & -0.14 & $0.29^{* *}$ & 0.03 & -0.14 & 0.09 & $0.22^{*}$ \\
French & -0.05 & 0.04 & 0.03 & 0.07 & -0.02 & -0.13 \\
School Subject & & & & & -0.13 \\
German & $0.36^{* *}$ & 0.06 & $-0.37^{*}$ & $-0.20^{*}$ & $-0.54^{* * *}$ & 0.17 \\
English & $0.40^{* *}$ & 0.13 & $-0.41^{* * *}$ & -0.17 & $-0.44^{* *}$ & 0.01 \\
French & 0.20 & 0.20 & 0.01 & -0.10 & -0.04 & 0.13 \\
\hline
\end{tabular}

Note. Separate models were run for each emotion. Sex was coded 0 for female and 1 for male.

School subjects were dummy coded with mathematics as reference category. $N=480$ assessments (120 students, with four assessments per student related to the domains of mathematics, German, English, and French). Coefficients are unstandardized regression coefficients.

$* p<.05 . * * p<.01 . * * * p<.001$. 
Table 6

Two-level Multiple Regression Analyses for State Achievement Goals as Predictors of State Achievement Emotions

\begin{tabular}{|c|c|c|c|c|c|c|}
\hline Predictor variable & Enjoyment & Pride & Anxiety & Shame & Anger & Boredom \\
\hline \multicolumn{7}{|l|}{ Level 1} \\
\hline \multicolumn{7}{|l|}{ Achievement goals } \\
\hline Mastery goals & $0.22^{* * * *}$ & $0.15^{* * * *}$ & -0.01 & -0.01 & $-0.12^{* *}$ & $-0.29^{* * *}$ \\
\hline $\begin{array}{l}\text { Performance-approach } \\
\text { goals }\end{array}$ & $0.13^{* *}$ & $0.18^{* * * *}$ & 0.03 & $0.07^{*}$ & 0.03 & -0.05 \\
\hline $\begin{array}{l}\text { Performance-avoidance } \\
\text { goals }\end{array}$ & 0.02 & -0.01 & $0.10^{*}$ & $0.07^{*}$ & 0.06 & 0.05 \\
\hline \multicolumn{7}{|l|}{ School Subjects } \\
\hline German & $0.19^{*}$ & 0.06 & $-0.15^{*}$ & $-0.21^{* *}$ & $-0.23^{*}$ & -0.04 \\
\hline English & $0.22^{* *}$ & 0.07 & $-0.24^{* *}$ & $-0.19^{* *}$ & $-0.26^{*}$ & -0.05 \\
\hline French & 0.09 & 0.03 & -0.02 & -0.09 & -0.07 & -0.03 \\
\hline \multicolumn{7}{|l|}{ Level 2} \\
\hline \multicolumn{7}{|l|}{ Demographic Variables } \\
\hline Sex & $0.20^{*}$ & 0.15 & -0.05 & 0.07 & 0.11 & -0.01 \\
\hline Age & -0.01 & 0.16 & 0.09 & 0.07 & 0.10 & 0.19 \\
\hline \multicolumn{7}{|l|}{ Academic achievement } \\
\hline Mathematics & 0.08 & -0.14 & -0.08 & -0.09 & $-0.16^{*}$ & -0.07 \\
\hline German & 0.18 & -0.19 & -0.04 & -0.04 & -0.18 & -0.10 \\
\hline English & -0.13 & 0.17 & -0.07 & 0.02 & 0.08 & 0.16 \\
\hline French & -0.04 & 0.03 & 0.09 & 0.06 & 0.05 & -0.06 \\
\hline
\end{tabular}

Note. Separate models were estimated for each emotion. Sex was coded 0 for female and 1 for male. School subjects were dummy coded with mathematics as reference category. $N_{\text {Level } 1}=$ 1,409 (assessments within students), $N_{\text {Level } 2}=120$ (students). Unstandardized coefficients are shown.

$* p<.05 . * * p<.01 . * * * p<.001$. 
Achievement Goals

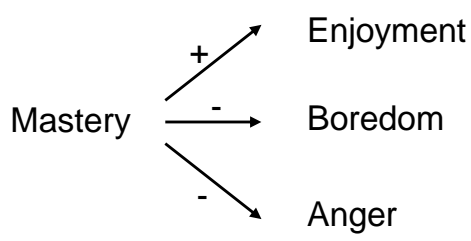

Performance-approach

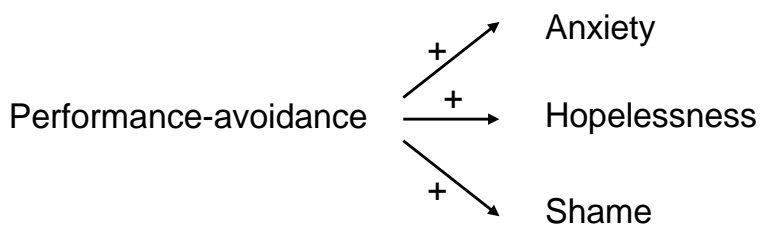

Figure 1. Theoretical propositions on the relations between achievement goals and achievement emotions (adapted from Pekrun et al., 2006, 2009). 